\title{
Customer Satisfaction in Business to Consumer (B2C) E-commerce: A Comparative Study of Turkey and Pakistan
}

\author{
Sahal M. SHEIKH ${ }^{*}$, Mehmet BASTI $^{* *}$
}

\begin{abstract}
The World Wide Web and the medium of internet have invaded the world from all directions and it has transformed the business and economies into series of electronic financial transactions. E-Commerce is a relatively new born phenomenon and this study explores into the realm of Business-to-Customer e-commerce customer satisfaction in Pakistan and Turkey. The methodology used to extract primary data is the contingency valuation approach; questionnaire. In total 205 Questionnaire were filled and collected online which constituted 110 surveys from Pakistan and 95 surveys from Turkey. The study uses descriptive analysis and also two sample t-test to test the hypothesis of the study which is that there is no difference in the levels of Business-to-Customer e-commerce customer satisfaction in Pakistan and Turkey. The findings of the study reveal that there is no significant difference between the levels of Pakistan and Turkey as the individual factors affecting e-commerce customer satisfaction do not differ in intensity. There are few differences but mainly the countries are on converging paths in this context.
\end{abstract}

Keywords: Customer Satisfaction, E-Commerce, Business-to-Customer

JEL Code Classification: L81, M31, M37

UDC: $339.72(560+549.1): 004$

\footnotetext{
*MA, Fatih University. E-mail: sahalmanzoor@gmail.com

** Corresponding Author. Assistant Professor, Management Department, Fatih University, Turkey.

E-mail: mbasti@fatih.edu.tr

Copyright (C), 2015 International Ataturk Alatoo University.
} 


\section{Introduction}

In this consumer driven world economies it is very vital to comprehend the needs and wants of the potential consumers at large and also to probe into how satisfied or happy they are from an organization's product or service.

Internet and the World Wide Web have amended the business competitions and tailored the Business-to-Consumer (B2C) relationship by introducing an innovative retailing platform that provides for electronic one-on-one communication with the customers. The Internet possesses a capability of revolutionizing the business conventional format and the customer service experience in many ways.

The availability of uncountable products and their respective pricing information on the internet lets customers to efficiently and easily become knowledgeable and proactive while shopping. It is of utmost importance according to previous literatures to understand consumers and their utilization of the Internet for the organizations in cyberspace businesses for sustainable success and growth. It is found out that success in superior economic returns is attributed as a result of satisfied customers. The use of electronic technology in strategic ways can boost to improve the overall customer to business relationship and can yield customer satisfaction which could serve as the basis of competition within the cyberspace industry and result innovative businesses methods for a firm (Hair \& Keep, 1997).

As per the report of Neilsen 2014, the internet penetration rates in Pakistan and Turkey are $15 \%$ and $43 \%$ respectively. These rates are very low compared to developed countries. The pre-requisite to e-commerce is the use and acceptance of internet and therefore with these low rates in both countries it is very vital to conduct researches and promote projects to make a way through for e-commerce industry (Neilsen, 2014).

\section{The Dynamics of E-Commerce}

This part of the study will introduce to key definitions of e-commerce and the history of its evolution. It will explain the general trends in business-to-customer model and also will scrutiny other e-commerce models. The two countries under consideration; Turkey and Pakistan, will also be investigated in context of ecommerce acceptance and the satisfaction of the customers achieved by B2C organizations.

\subsection{The Evolving Definitions of E-Commerce and its Contrast to E-Business}

E-commerce is a phenomenon which has evolved during its origination and has set to have differing definition due to lack of consensus between many scholars. However there is unanimous agreement on a very fundamental level which is that e-commerce is set to be defined as commercial transactions that are conducted on the Internet electronically. The problem arises when a concrete and comprehensive definition is poised by scholars (Ernst and Young, 2001). 
Organization for Economic Co-operation and Development (OECD) has given two definitions for e-commerce. One is narrow and concrete and one is descriptive and broad. OECD broadly defines e-commerce as the sale or purchase of a product or service, which could be among households, businesses, governments, individual consumers, and other private or public companies, which is mediated through computer networks. The important point to be noted in this definition is that goods and services should be ordered over these mentioned computer online networks, but the payment and the final delivery can be carried out off or on-line. This broad definition includes the orders placed or received by customer on any online device which can be used to make automated transactions like telephone, Electronic Data Interchange (EDI), Internet applications. On the other hand the narrower definition by OECD was very similar to the above mentioned definition but it Excluded orders placed or received over the telephone, e-mail, or facsimile (OECD 1999a; OECD, 2000a; OECD 2000b).

According to the World Trade Organization (WTO), e-commerce is a phenomenon which realizes advertisement, production, distribution and sales of goods and services via networks requiring telecommunication (Jewels et al, 2001).

Chaffey (2009: 10), explained e-commerce is the exchange of electronic mediated information between a firm and its external stakeholders. According to the author e-commerce has two paradigms which are buy-side e-commerce and sell-side e-commerce. Buy side e-commerce is the interaction of organization and its suppliers whereas sell-side e-commerce is the interaction between organization and its customers.

E-business and e-commerce are often intermingled ideas which have very thin borders to separate them. In e-business, Integrated Computerized Technology (ICT) is used to augment a business. There are three main processes which are enhanced in e-business namely firstly the production processes, which include production control processes and electronic linkages with the suppliers. Secondly customeraimed processes, which include marketing and promotional efforts, internet sales, customers' payments and purchase order. Lastly, the internal management processes which include the following programs: training, employee services, recruiting, internal communication, and video-conferencing. E-business is a term which would generally be found to be used in two main ways within an organization. First it is used in a company's strategy and operations and second it is used as an adjective to depict businesses that work online. (Chaffey, 2009: 13).

After carefully understanding the different definitions of e-commerce and its evolution over time we can give a generalized definition of e-commerce as a type of business model, or fragment of a integrated business model, that allows the use digital information and electronic communications processing technology to transform, create, and re invent relationships in business transactions for the purpose of value creation among or between companies and between individuals and firms. 


\subsection{E-Commerce Models}

The type of e-commerce model that should be employed depends on the parties involved. E-commerce can be categorized into models depending on this matrix intersection that is mentioned below in Table 1. The main categories are B2C, B2B and $\mathrm{C} 2 \mathrm{C}$.

Table 1. Matrix of Models of E-Commerce

\begin{tabular}{lccc}
\hline & Business & Consumer & Government \\
\hline Business & $\mathrm{B} 2 \mathrm{~B}$ & $\mathrm{~B} 2 \mathrm{C}$ & $\mathrm{B} 2 \mathrm{G}$ \\
Consumer & $\mathrm{C} 2 \mathrm{~B}$ & $\mathrm{C} 2 \mathrm{C}$ & $\mathrm{C} 2 \mathrm{G}$ \\
Government & $\mathrm{G} 2 \mathrm{~B}$ & $\mathrm{G} 2 \mathrm{C}$ & $\mathrm{G} 2 \mathrm{G}$ \\
\hline
\end{tabular}

Source: The Economist, 26 Feb 2000

The B2B model encompasses the transactions for purchasing, ordering, and for administrative works between entities. B2B deals with trading goods, such as, professional services, business subscriptions, wholesale dealings and manufacturing. It is also possible in the B2B model that a business may exist between virtual firms, in which no party has any physical existence. In these examples, transactions are made only through the Internet (Chaffey, 2009).

B2C model is described as any transaction or business that directly gives its products to the end-consumers without any intermediately. B2C applies to any organization that indulges in selling its goods or services to the consumers over the Internet medium. These sites contain information regarding the goods and services offered which stored in a database and is represented as online catalogues. The B2C model is a broad model which also includes services travel services, online banking, and online health services and information (Chaffey, 2009: 26; Yahia, 2005; Malhotra \& Singh, 2009).

The $\mathrm{C} 2 \mathrm{C}$ model is the transaction among consumers. In this model a consumer sells/buys directly from another consumer. EBay and www.bazee.com are the two widely used examples of online auction that provide a consumer a platform or arena to market and sell their products to other individuals. The individual who wants to sell a particular product should pay a fixed fee to the online platform to sell his/her products. On the other hand, the buyer can bid on the online auction without paying any fee (Chaffey, 2009: 27; Moxon, 2001).

\subsection{The Notion of Business-to-Customer E-commerce}

The worldwide expansion of the internet should be considered an integral part of any country's economy as the world has been revolutionized by technology and the near future is e-commerce and e-business. The increasing confidence and trust in engaging in purchasing online are a source of initiatives to support the development of the digital global economy. 
According to a report by the Interactive Media in Retail Group (IMRG, 2014), ecommerce statistics reveal a staggering rate at which this industry is developing as globally, the sales of $\mathrm{B} 2 \mathrm{C}$ e-commerce accounted for more than US 1.2 trillion dollars in 2013. Currently $40 \%$ of the worldwide internet users have bought products online through mobiles, computers, tablets or other devices. This coins the total number of Internet users to be 3.5 billion from around 2.2 billion at the end of 2012 (UNCTAD 2014). Mobile commerce which is an extension of ecommerce to smart phones is another trend to study in terms of e-commerce facts and figures. In 2013, US mobile revenue amounted to approximately 38 billion dollars (Satista, 2015).

The US claims to be the world's single biggest e-commerce market according to IMRG (2014), followed by the United Kingdom and Japan. IMRG predicts that growth rates in these countries will be nearly 10-15\% annually. However, China's e-commerce sale is currently experiencing a growth of more than $130 \%$. It is supposed to be only a matter of time, when this Asian giant becomes the largest single market in the world superseding US, UK and Japan.

In terms of regions, Europe has the upper hand as it currently stands to be the largest e-commerce market in the world. According to a report by (European MultiChannel and Online Trade Association, 2014), European B2C e-commerce sales posted an estimated 307 billion USD in 2011 which helped them to surpass the North America which accounted for 297 billion USD. IMRG (2014) also argued that Italy, France, Russia, Turkey, Spain and Poland the fastest-growing markets in European region.

\subsection{The History, Present and Future Trends of E-commerce}

The birth of e-commerce dates back to the year 1960's. E-commerce commenced with the introduction of EDI, which facilitates information exchanges and maintains relations between companies via specifically designed group networks. EDI is not outdated and is still being used in the Business-to-business model of e-commerce. The Internet and the World Wide Web have significantly contributed to the development of e-commerce (Meyer and Taylor, 2000).

There are two pillars which instigated the progress of ecommerce since its inception. The first is the advancements in information technology. The second pillar is the global motto of globalized world and trade with market liberalization policies. Furthermore, the need and want of economic interdependency among countries contributed to the formation of e-commerce (Korkmaz, 2002).

To understand the trend of e-commerce it is very important to understand what impact has time on the level of e-commerce activity. Figure 1 displays the measures of e-commerce activity over time. From recent years the technological acceptance and growth rates have seen massive increases worldwide. 


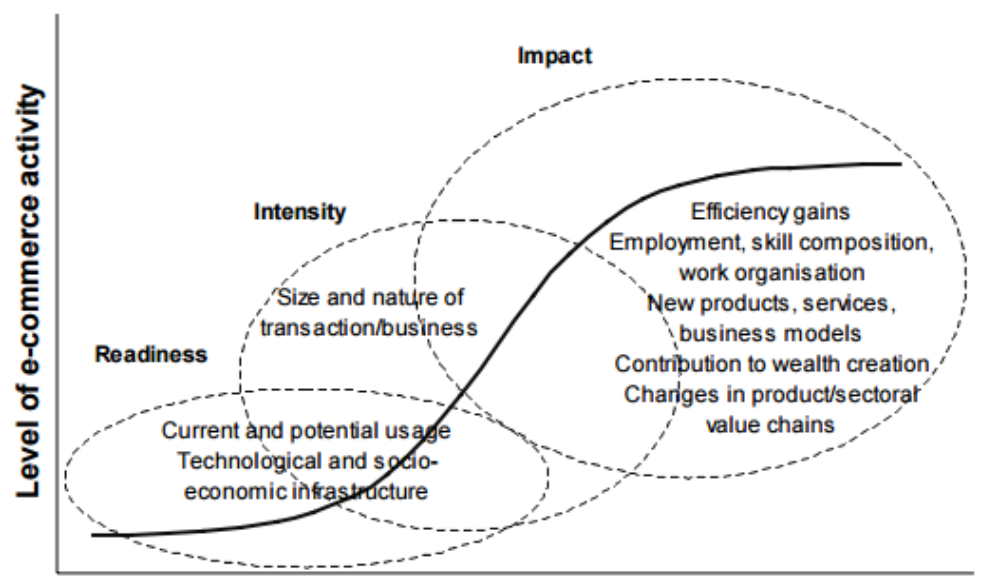

Time

Figure 1. E-Commerce Level of Activity over Time Source: OECD 2000c

Detailed analysis of the world in Table 2 shows the internet penetration in the year 2014. As we can observe that Pakistan has only $15 \%$ internet penetration while Turkey has $57 \%$. The highest internet penetration rates are observed in Denmark and Finland with $97 \%$.

Table 2. Internet Penetration in 2014 Selected Countries in the World

\begin{tabular}{|l|c|l|c|}
\hline \multicolumn{1}{|c|}{ Country } & Internet Penetration & \multicolumn{1}{c|}{ Country } & Internet Penetration \\
\hline Denmark & $97 \%$ & Hungary & $75 \%$ \\
\hline Finland & $97 \%$ & Malaysia & $67 \%$ \\
\hline Netherlands & $96 \%$ & Romania & $51 \%$ \\
\hline Canada & $95 \%$ & Russia & $61 \%$ \\
\hline Sweden & $95 \%$ & Greece & $60 \%$ \\
\hline South Korea & $92 \%$ & Italy & $59 \%$ \\
\hline United Kingdom & $90 \%$ & Turkey & $57 \%$ \\
\hline Austria & $87 \%$ & Brazil & $54 \%$ \\
\hline Germany & $87 \%$ & Egypt & $53 \%$ \\
\hline United States & $87 \%$ & Mexico & $49 \%$ \\
\hline Japan & $86 \%$ & China & $47 \%$ \\
\hline France & $83 \%$ & India & $20 \%$ \\
\hline Argentina & $75 \%$ & Pakistan & $15 \%$ \\
\hline
\end{tabular}

Source: Adapted by Neilsen, 2014

To understand e-commerce the trends should be analyzed and studied in order to comprehend the preferences of the customers over the world. Table 3 illustrates the online purchase intention growth rates for the years 2011 to 2014 . These figures are the global average and show which fields or investment is more likely to be made by online consumers when they engage in e-commerce transactions. With the world going global and the media playing its part to show the beauty of other 
countries, e-commerce has been largely benefited with e-tourism which includes flight tickets, hotel reservations and event tickets. This can be seen from the Table 3 as there are on the top of the list. However, the event tickets secure a consolidated standing in this table which range from buying sports oriented tickets for matches to concerts tickets.

\section{Table 3. Popular E-Commerce Activities in 2011 and 2014}

\begin{tabular}{|l|c|c|}
\hline Category & $\mathbf{2 0 1 1}$ & $\mathbf{2 0 1 4}$ \\
\hline Event Tickets & $22 \%$ & $41 \%$ \\
\hline E-Books & $15 \%$ & $34 \%$ \\
\hline Computers software & $9 \%$ & $27 \%$ \\
\hline Tours and Hotel Reservation & $27 \%$ & $44 \%$ \\
\hline Sporting Goods & $15 \%$ & $31 \%$ \\
\hline Toys and Doll & $13 \%$ & $29 \%$ \\
\hline Airline Tickets and Reservation & $33 \%$ & $48 \%$ \\
\hline Videos, DVDs, Games and Music & $15 \%$ & $28 \%$ \\
\hline Computer Hardware & $18 \%$ & $30 \%$ \\
\hline Baby Supplies & $8 \%$ & $20 \%$ \\
\hline Car, Motorcycles and Accessories & $8 \%$ & $17 \%$ \\
\hline Electronic Equipment & $27 \%$ & $34 \%$ \\
\hline Cosmetics & $25 \%$ & $31 \%$ \\
\hline Groceries & $22 \%$ & $27 \%$ \\
\hline Clothing, Accessories and Shoes & $42 \%$ & $46 \%$ \\
\hline Mobile Phone & $26 \%$ & $33 \%$ \\
\hline
\end{tabular}

Source: Adapted by Neilsen, 2014

It is expected that by the year 2018 the estimated sales in US billion of dollars will be 2,356 billion. This shows how huge this business platform is evolving to become and how all the enterprises worldwide are adopting e-commerce in their business to facilitate and reach a wide variety of consumers.

\subsection{An Overview of Country Profile in The Light of B2C E-Commerce: Pakistan and Turkey}

Jennex et al. (2004) discussed in their study the need of appropriate infrastructure for e-commerce in developing countries and the factors that turn developing setting. This study concluded that e-commerce is filling the technology gap between out to be help the B2C enterprises to be successful in this natural environmental the big and small enterprises and providing even playing field to every new start-up to expand and grow particularly in developing countries.

Seyal et al. (2004) researched the adoption rate of e-commerce and internet facilities in small and medium enterprises (SMEs) in Pakistan. This study also probed into the factors that affect the e-commerce adoption in SMEs in Pakistan. The research concluded that $80 \%$ of Pakistan's SMEs have an internet account to provide the basis of e-commerce. The study also found out that approximately $46 \%$ of the SMEs have "above average" adoption of e-commerce. In addition to this the 
factors that were examined included organizational culture, motivation to adopt ecommerce, technological availability, environmental concerns and management support functions.

Blythe (2006) discussed in his study the Electronic Transaction Ordinance (ETO) which was passed in the fiscal year 2002 in Pakistan concerning the e-commerce and e-government rules and regulations and their implementations. According to the author ETO lays down the foundation for legal framework and validates the electronic messages, records and signatures.

Celik and Yilmaz (2011) researched in this article the acceptance of e-commerce by the Turkish customers. They extended the Technological Acceptance Model (TAM) which is a very vital and significant modeling approach in the field of information technology. The authors added perceived information quality, enjoyment, trust, service and system quality to the already existing TAM model. The findings suggested that the variables added to the TAM model are significant and have a notable effect on acceptance of internet shopping. The article also highlights the birth of e-commerce in Turkey in the year 1998.

Kaynak et al. (2005) investigated the adoption of e-commerce in SMEs in Turkey and also identified the significant factors that play a vital part in e-commerce adoption. The study collected data from 237 companies in Turkey which had access to internet. It was found in the research that e-commerce positively influenced companies to adopt it because the net benefits outweighed the associated net costs. According to the results of this article, e-commerce has an advantage of external communication benefits to a B2C and also provides clusters of information that helps in product and market research development.

\section{Customer Satisfaction}

The need for identification of problems associated with customer satisfaction in ecommerce and the methodology incorporated to evaluate it plays an integral role in determining how to improve services provided by B2C organizations. Consumer satisfaction plays a pivotal role in the evaluation cycle of a consumption, shopping or service or product usage and therefore is useful in extracting consumer responses in the long-term (Gronroos, 1991). Both the business management and scientific literature realms have signaled a cohesive interest in fulfilling customer needs to determine the purchase behavior.

\subsection{The Conceptualization of Customer Satisfaction and Prior Studies}

The first researches on customer satisfaction go back in time of Cardozo (1965) and Howard and Sheth (1969). These scholars investigated the influence and impact of expectations on satisfaction. These studies are known to be the origination of scientific interest in the phenomenon satisfaction (Campo and Yague, 2009). 
Customer satisfaction is a gauge of performance of perceived organizational product relative to a buyer's expectations. If the product's performance fails to meet expectations of the consumer, then the customer is dissatisfied. If performance copes up with the expectations, then the customer is satisfied. If performance exceeds the levels of expectations, then the customer is said to be highly satisfied and delighted. Keeping customers satisfied serves as the best competitive advantage against competitors. Customers are found loyal and are prepared to pay premium for a product. In addition to this they become excellent external marketers for the organization (Gupta et al., 2003).

Gupta and Zeithaml (2006) proposed a theoretical framework for customer satisfaction in his article. According to the author there are five important variables that have a critical impact on the level of customer satisfaction. The research concluded that all of the five variables have a positive and significant impact on the customer satisfaction. The five factors that affect customer satisfaction are listed in Figure 2 below:

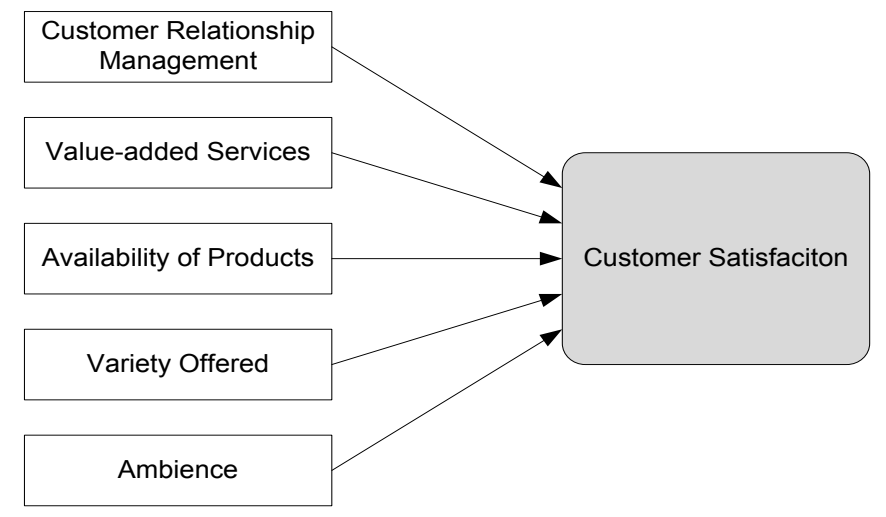

Figure 2. Factors Effecting Customer Satisfaction

Source: Gupta and Zeithaml (2006)

Giese and Cote (2000) and later adaptations by Moliner (2004) coined that consumer satisfaction is an approach based on two distinct criteria which are conceptual and referential criterions. Conceptual criterion explains satisfaction through types or processes of responses generated by consumers. Whereas, a referential criterion reflects the aspects of a situation in which a response may occur. It is very important to understand that these criterions are not necessarily mutually exclusive and that the main definitions in the previous studies may highlight complementary and different approaches. Figure 3 below illustrates customer satisfaction described by the two criterions.

Furthermore, recent customer satisfactions researches coincide with the initial researches and indicate that expectation is the most direct determinant of consumer satisfaction. This is followed by an addition of perceived performance. 
Parker and Mathews, (2001) designed the value percept theory which describes satisfaction as an emotional response that is instigated by an evaluative cognitive process. This is in a contradiction with earlier literature which defined satisfaction as an evaluative judgment (Oliver, 1997).

Moreover, Swan and Combs (1976) were one of the first scholars to argue that consumer satisfaction is correlated with performance driven expectations and dissatisfaction occurs when performance does not meet the expectations and fall short of it.

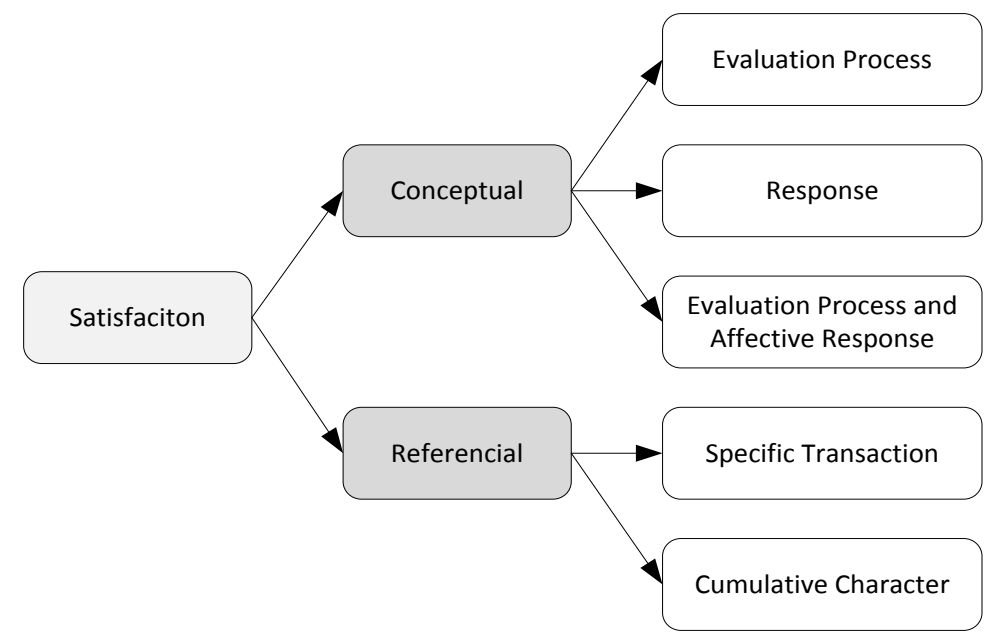

Figure 3: Conceptual and Referential Criterion of Satisfaction

Source: Adapted from Giese and Cote (2000) and Moliner (2004)

The more conventional and traditional models define customer satisfaction implicitly as a result of cognitive processes, while recent studies improving on the conceptual developments put forward that effective processes can also contribute to the estimation and definition of consumer satisfaction (Westbrook \& Oliver, 1991).

\subsection{E-Commerce Customer Satisfaction}

Singh (2002) underlined the importance of e-services to the B2C e-commerce business. According to the author this relationship has a positive impact on sales and customer relationship management. The findings of this research concluded that services which the customers cherish include customer-queries answering as fast as possible, search support, transactions and order placement ease, convenient e-pay system, transparent and efficient e-transaction record and trust by e-assurance.

Chen and Dubinsky (2003) analyzed that one of the key factors that affects B2C ecommerce is the information quality on the website. The customers always want 
more and more well detailed and importantly true information about the products being displayed on the websites and therefore the information provided by the B2C organization plays a critical role in customer satisfaction. Another factor related to this is the comprehend ability of the information on the website. Gefen and Straub (2003) explained that customer trust is one of the critical factors that affect customer satisfaction. The authors explained trust as when a customer is doing transaction with an organization; he/she will meet their expectations and will not indulge in any fraudulent or undesirable terms.

Shankar et al. (2003), set out to research whether there is a profound difference in the levels of customer satisfaction from online and offline purchases. They also investigated the customer loyalty differences from offline and online buying methods. The study found out that there is no mark difference between the customer satisfaction levels between the online and offline buying method however the levels of loyalty shown by customers from online buying is greater than the offline buying customers. They also found out that the relationship between customer loyalty and satisfaction is that of a reciprocal and that each concept positively reinforces the other.

Zhang et al. (2006), came to a conclusion that the important and significant factors that affect e-commerce satisfaction include perceived convenience and security that the website offers and the customer's own skills and experiences. Lin (2007) highlighted the importance and impact of website quality in terms of design and information provided on it for customer satisfaction in B2C e-commerce. This research also found out that the interactivity of the website plays an important role in satisfying customers and making them loyal in regards to enticing them to repurchase from the same website. Other factors that are also important in this regard are security and presence in social media.

Bai et al. (2008) concluded that e-commerce consumers demand privacy when they are engaged in a buying act with the company through internet for satisfaction. The perceived privacy according to these writers meant that a consumer's personal information should be kept safe and handled with care, and no third party should be able to use or view the personal information of the consumers. The ability to retain and store the personal information and use it adequately is one of the primary concerns of a customer when it comes to the phenomena of perceived privacy.

Jianchi and Xiaohong (2009) stated that there are five variables that positively affect customer satisfaction on e-commerce basis. These variables were the design of the website, the service that they provide to the user, the information quality that the website has, website intelligence and security. Eid (2011) researched that consumer loyalty in B2C e-commerce strongly and positively influenced by customer satisfaction. However the customer loyalty is weakly influenced by consumer trust. 
Brilliant and Achyar (2013) investigated that on a global level the sales of ecommerce and this study also concluded that the quality of information on an ecommerce website affects e-commerce satisfaction and also that e-commerce trust affects the consumer loyalty of the B2C e-commerce.

According to Subramanian et al. (2014), higher customer satisfaction in ecommerce can bring substantial benefits, such as repeat purchase, good word of mouth, and profit increase.

Jie et al. (2015) studied on product delivery service provider selection and customer satisfaction. According to authors findings substantive selective criteria should include consideration of product delivery service providers' hard and soft infrastructure. In addition they emphasize that flexibility is main criteria for strengthen the relationship between e-retailers and delivery service providers to satisfy the e-customers.

\subsection{Important Studies on E-Commerce and Customer Satisfaction in Pakistan and Turkey}

Sulaiman et al. (2007) investigated that the major factor that inhibits B2C organization in Pakistan from adopting e-commerce is the trust factor that is very difficult and vulnerable variable in a country like Pakistan where levels of corruptions and fraudulent activities are on a high. Pakistan according to this study has turned due to its political instability a very risk averse nation and therefore consumers engage in as safe as possible medium of transaction as possible. Another very important factor that hinders e-commerce is the use of liquid cash instead of credit cards which in turn inhibits e-commerce business.

Kaleem (2008) investigated the use of internet banking in Pakistan and the acceptance of e-commerce in a developing country. The benefits of e-commerce and online banking model are discussed in this articles which includes saving time and reducing transaction costs therefore it should be an area where future investment would probably be very popular and profitable.

Lightner et al. (2010) examined the difference between the e-consumers of Turkey and USA students and provided country specific guidelines for both the B2C ecommerce organizations. This article talks about the appropriate changes and amendments required according to the specific country and their citizens in ecommerce so suit the preferences and wants respectively. This means that Turkish students would require different needs and different type of websites starting from the language to the web-lay out.

Barutcu (2008) studied the importance of online store loyalty in electronic retailing industry and explained the drivers of online store loyalty. According to the author study results showed that e-customer satisfaction, trust and reward have very important role to develop online store loyalty. 


\section{Methodological Process and Research Findings}

Figure 4 entail following constructs and variables whose relationship are to be tested and examined in this research while providing an insight into the comparison of Pakistan and Turkey B2C e-commerce customer satisfaction. The variables that affect e-commerce B2C customer satisfaction levels are diagrammatically shown below in Figure 4:

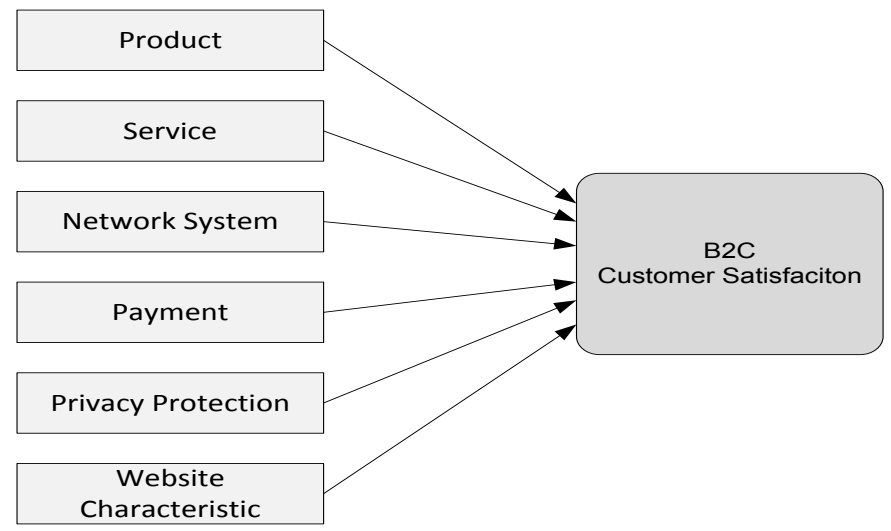

Figure 4. B2C Customer Satisfaction Model

The essence of this study is to compare and contrast the e-commerce B2C customer satisfaction levels in both Pakistan and Turkey. This research uses the constructs that effect customer satisfaction for both countries and then will check if the two countries differ or not in terms of e-commerce B2C satisfaction.

$\mathrm{H}_{\mathrm{o}}$ : There is no difference between the levels of B2C e-commerce customer satisfaction between Pakistan and Turkey.

$\mathrm{H}_{\mathrm{A}}$ : There is a difference between the levels of B2C e-commerce customer satisfaction between Pakistan and Turkey. The mathematical representation of the null and alternate hypothesis is given below:

\subsection{Research Methodology}

This study is based on a research in two countries namely Pakistan and Turkey. The research employs a quantitative technique that is questionnaire to collect the necessary data and information regarding the study. A total of 229 respondents were asked to fill the questionnaire by e-mail and over social media such as Facebook and LinkedIn. 124 respondents answered from Pakistan and 105 from Turkey. 110 responses were selected from Pakistan out of 124 and 95 from out of 105 were selected from Turkey. The reason for this was because the questionnaire had the first question to see whether the respondent has an online shopping experience or not and those who answered "no" were discarded from the analysis. Therefore the total sample amounted up to 205 participants. The sampling done 
for this research was selective and convenient sampling. This means that the respondents were chosen according to the ease of being approached as well as having a first-hand experience of online shopping. The questionnaire was designed and distributed online to be parallel with the essence of the research which is the online realm of activities.

The respondents will be taken as sample and representatives of the entire countries and an analysis will be conducted that will explore the similarities and differences between the $\mathrm{B} 2 \mathrm{C}$ e-commerce satisfaction in the two countries under consideration.

\subsection{Data Collection and Choice of Research Analysis}

Primary data was collected in the form of 53 questions posed in the survey questionnaire and were there upon translated into excel coding sheet which was used for generating meaningful finding of this research. Four different sections namely General, Customer Satisfaction, Repurchase Behavior and Demographics were made comprising of non-directing and unbiased questions so that consistent complete information is extracted from the respondents.

Multiple choice, grid and rank questions were designed in the survey so that the questionnaire was systematic and consistent in then question styles. These types of questions were also used so that the respondents can easily comprehend the questions. Only two dichotomous questions were asked which were regarding the use of online shopping and gender of the participants. This study uses the unit of analysis as one individual that filled the questionnaire.

Contingency valuation approach entails many important biases which were kept in mind while sketching the questions for the questionnaire. The two biases that were likely to affect this study were the hypothetical and embedding bias.

A hypothetical bias is where respondents are put into a self created hypothetical situation which leads to "out of thin air" answers. This bias was hindered by not including hypothetical based questions in the research.

An embedding bias is one of the most important and serious biases that had should be dealt with. Embedding bias occurs when the answers have an affect due to the quality of information at disposal about the topic and question under study. Therefore information was provided carefully and personally all of the respondents were talked with and discussed with about the questions they filled after the respondents submitted their answers.

As a comparative analysis is set out to be conducted in this research, the inclusion of questionnaire as a means of extracting the data was helpful as it serves as a common base of comparison for the participants from both the countries. Therefore with the participants exposed to the same questions a statistical compare and contrast would be easier to design and probe into. The questionnaire 
also cuts down unnecessary information that is always on the cards when engaged in a qualitative technique compared to a quantitative technique.

As the hypothesis of this research is to compare and contrast the two countries under consideration, two sample t-tests was employed to explore that if the samples are different from each other or not. This statistic compares if the mean of the two samples are different from each other. Another reason to adopt this technique was due to the difference in the sample sizes. From Pakistan we have 110 participants and from Turkey we have 95. This technique allows unequal sample sizes and therefore it was the best fit and in line statistical technique to use. Plus it used in comparison studies in the literature and therefore it was adopted in this study.

\subsection{Profile and Characteristics of Respondents}

Table 4 summarizes the profiles of respondents. It can be seen in Table 4 that out of the total 205 participants (both Pakistan and Turkey) the majority of the participants lied in the age bracket 18-24 and 25-34. Therefore, on a whole the majority of the respondents fell in the young and middle age bracket.

\section{Table 4. Respondents' Profiles}

\begin{tabular}{|l|c|c|c|c|}
\hline \multirow{2}{*}{ Characteristics } & \multicolumn{2}{|c|}{ Pakistan } & \multicolumn{2}{c|}{ Turkey } \\
\cline { 2 - 5 } & \multicolumn{2}{|c|}{$\mathrm{N}=110$} & \multicolumn{2}{c|}{$\mathrm{N}=95$} \\
\hline Respondents' Gender & $\mathrm{F}$ & $\%$ & $\mathrm{~F}$ & $\%$ \\
\hline Male & 51 & 46.4 & 49 & 51.6 \\
\hline Female & 59 & 53.6 & 46 & 48.4 \\
\hline Age of Respondents & 47 & 42.7 & 45 & 47.4 \\
\hline $18-24$ & 48 & 43.6 & 29 & 30.5 \\
\hline $25-34$ & 12 & 10.9 & 16 & 16.8 \\
\hline $35-44$ & 2 & 1.8 & 5 & 5.3 \\
\hline $45-54$ & 1 & 0.9 & - & - \\
\hline 65 and over & \multicolumn{5}{|l|}{} \\
\hline Educational Levels of Respondents & 5 & 5.5 & 10 & 10.5 \\
\hline PhD & 61 & 55.5 & 32 & 33.7 \\
\hline Master Degree & 42 & 38.2 & 51 & 53.7 \\
\hline University & 2 & 1.8 & 1 & 1.1 \\
\hline High Schools & $\mathrm{F}$ & $\%$ & $\mathrm{~F}$ & $\%$ \\
\hline Occupation of Respondents & 6 & 5.5 & 1 & 1.1 \\
\hline Businessmen & 16 & 14.5 & 15 & 15.8 \\
\hline Managers & 43 & 39.1 & 45 & 47.4 \\
\hline Student & 23 & 20.9 & 19 & 20 \\
\hline Teacher / Academic & 9 & 8.2 & 4 & 4.2 \\
\hline Administrative Employee & 4 & 3.6 & 7 & 7.4 \\
\hline Laborers & 9 & 8.2 & 4 & 4.2 \\
\hline Not working & & &
\end{tabular}


Sahal M. SHEIKH \& Mehmet BASTI

Table 4 (cont). Respondents' Profiles

\begin{tabular}{|l|c|c|c|c|}
\hline \multirow{2}{*}{ Characteristics } & \multicolumn{2}{|c|}{ Pakistan } & \multicolumn{2}{c|}{ Turkey } \\
\cline { 2 - 5 } & \multicolumn{2}{|c|}{$\mathrm{N}=110$} & \multicolumn{2}{c|}{$\mathrm{N}=95$} \\
\hline Household Income of Respondents & $\mathrm{F}$ & $\%$ & $\mathrm{~F}$ & $\%$ \\
\hline 1000 USD below & 38 & 34.5 & 37 & 38.9 \\
\hline $1000-4999$ USD & 38 & 34.5 & 50 & 52.6 \\
\hline $5000-10,000$ USD & 14 & 12.7 & 8 & 8.4 \\
\hline 10,000 USD above & 20 & 18.2 & - & - \\
\hline Online Purchasing Duration & 30 & 27.3 & 13 & 13.7 \\
\hline under 1 year & 35 & 31.8 & 17 & 17.9 \\
\hline less than 2 years & 14 & 12.7 & 18 & 18.9 \\
\hline less than 3 years & 7 & 6.4 & 11 & 11.6 \\
\hline less than 4 years & 7 & 6.4 & 5 & 5.3 \\
\hline less than 5 years & 17 & 15.5 & 31 & 32.6 \\
\hline Over 5 years & 41 & 37.3 & 20 & 21.1 \\
\hline Shopping Involvement & 49 & 44.5 & 42 & 44.2 \\
\hline Minimal shopper (at least one time per year) & 13 & 11.8 & 25 & 26.3 \\
\hline Occasional shopper (1 to 8 per year) & 6 & 5.5 & 8 & 8.4 \\
\hline Core shopper (9 to 24 shopper per year) &
\end{tabular}

Table 4 indicates the educational levels of the respondents from both Pakistan and Turkey. The respondents from Pakistan and Turkey on a very high majority had at least bachelor's degree. The highest respondent category for Pakistan was the master's level education whereas in Turkey it was the bachelor's level degree.

The Table 4 indicates the occupation of the sample for this study. The highest category from Pakistan and Turkey was of students amounting to a number of 43 out of the total 110 Pakistani respondents and 43 out of 95 Turkish respondents. Table 4 displays the monthly household income of the respondents. We can note that the majority of people from Turkey pool of participants fall in the category 1000-4999 USD and majority of Pakistan respondents fall in the category of 1000 USD below.

\subsection{Descriptive Findings from Pakistan and Turkey}

The first question inquired which factors motivated the participant to shop online and the respondents were allowed to choose more than one option. As we can see from Table 5, 81 respondents from Pakistan checked the non availability of the desired product in their neighborhood, while only 29 Turkish respondents selected this option. The second highest category for Pakistan was favorable price and time saving which $23 \%$ of the respondent's marked while for Turkey it is the first category with $37.3 \%$ of the respondents selecting this option. The second question posed on the respondents was which factors if any would likely dissuade them from shopping online. This question also had the option of checking more than one option. 
Customer Satisfaction in B2C E-commerce: A Comparative Study of Turkey and Pakistan

Table 5. Online Purchasing Behaviors

\begin{tabular}{|c|c|c|c|c|}
\hline \multirow{3}{*}{$\begin{array}{l}\text { Characteristics } \\
\text { Factors Which Prompt Interest in On-Line Purchasing }\end{array}$} & \multirow{2}{*}{\multicolumn{2}{|c|}{$\begin{array}{c}\text { Pakistan } \\
\mathrm{N}=110 \\
\end{array}$}} & \multirow{2}{*}{\multicolumn{2}{|c|}{$\begin{array}{c}\text { Turkey } \\
\mathrm{N}=95 \\
\end{array}$}} \\
\hline & & & & \\
\hline & $\mathbf{F}$ & $\%$ & $\mathbf{F}$ & $\%$ \\
\hline Not available in neighborhood & 81 & 38.0 & 29 & 17.5 \\
\hline More favorable price & 49 & 23.0 & 62 & 37.3 \\
\hline Higher quality product & 21 & 9.9 & 6 & 3.6 \\
\hline Time saving, home delivery, etc. & 48 & 22.5 & 63 & 38.0 \\
\hline None of the above & 10 & 4.7 & 5 & 3.0 \\
\hline Other & 4 & 1.9 & 1 & 0.6 \\
\hline \multicolumn{5}{|l|}{ Factors Which Dissuade Online-Shopping } \\
\hline No need & 16 & 5.0 & 10 & 3.4 \\
\hline Preference for direct purchasing in shops & 39 & 12.1 & 13 & 4.4 \\
\hline Lack of choice of services or products on-line & 25 & 7.8 & 19 & 6.5 \\
\hline Lack of knowledge/difficulty of access to the service & 20 & 6.2 & 19 & 6.5 \\
\hline Delivery problems & 36 & 11.2 & 39 & 13.3 \\
\hline Payment problems & 47 & 14.6 & 39 & 13.3 \\
\hline Extra shipment or delivery charges & 41 & 12.8 & 41 & 13.9 \\
\hline Apprehension on personal data protection & 20 & 6.2 & 34 & 11.6 \\
\hline Lack of confidence in after sale service & 51 & 15.9 & 48 & 16.3 \\
\hline Limited broadband accessibility & 2 & 0.6 & 1 & 0.3 \\
\hline Absence of advice during purchase & 8 & 2.5 & 28 & 9.5 \\
\hline I am not dissuaded from buying online & 10 & 3.1 & 3 & 1.0 \\
\hline Other & 6 & 1.9 & 0 & 0.0 \\
\hline \multicolumn{5}{|l|}{ Activities Respondents Engage in Online } \\
\hline Online shopping & 71 & 16.9 & 66 & 17.4 \\
\hline Online research into goods and services & 62 & 14.7 & 44 & 11.6 \\
\hline Listening to radio, watching television or reading press & 62 & 14.7 & 67 & 17.6 \\
\hline Downloading music, videos, games & 83 & 19.7 & 62 & 16.3 \\
\hline Using online banking or other financial services & 49 & 11.6 & 61 & 16.1 \\
\hline Participating in social networks & 91 & 21.6 & 78 & 20.5 \\
\hline Other & 3 & 0.7 & 2 & 0.5 \\
\hline Goods and Services Bought Online by Respondents & $\mathbf{F}$ & $\%$ & $\mathbf{F}$ & $\%$ \\
\hline Fresh food products & 6 & 2.0 & 6 & 1.6 \\
\hline Foodstuffs other than fresh products & 10 & 3.3 & 18 & 4.9 \\
\hline House-hold goods (furniture, toys etc) & 35 & 11.6 & 50 & 13.7 \\
\hline Medicines & 3 & 1.0 & 15 & 4.1 \\
\hline Films, music & 25 & 8.3 & 42 & 11.5 \\
\hline Books, periodicals & 43 & 14.2 & 78 & 21.3 \\
\hline Electronic equipment or computer equipment & 55 & 18.2 & 52 & 14.2 \\
\hline Financial services & 20 & 6.6 & 26 & 7.1 \\
\hline Tourism services & 53 & 17.5 & 62 & 16.9 \\
\hline Professional services (e.g. accountant) & 15 & 5.0 & 4 & 1.1 \\
\hline Health services & 11 & 3.6 & 11 & 3.0 \\
\hline Other & 26 & 8.6 & 2 & 0.5 \\
\hline
\end{tabular}


Sahal M. SHEIKH \& Mehmet BASTI

Table 5 (cont). Online Purchasing Behaviors

\begin{tabular}{|l|c|c|c|c|}
\hline \multirow{2}{*}{ Characteristics } & \multicolumn{2}{|c|}{ Pakistan } & \multicolumn{2}{c|}{ Turkey } \\
\cline { 2 - 5 } Mode of Payments Preferred by Respondents & $\mathbf{N}=\mathbf{1 1 0}$ & \multicolumn{2}{c|}{ N=95 } \\
\hline Credit or debit card & $\mathbf{F}$ & $\mathbf{\%}$ & $\mathbf{F}$ & $\mathbf{\%}$ \\
\hline Prepaid card or on-line credit account & 82 & 52.9 & 86 & 50.3 \\
\hline Electronic money transfer & 11 & 7.1 & 14 & 8.2 \\
\hline Cash on delivery & 11 & 7.1 & 31 & 18.1 \\
\hline Mobile payment methods & 38 & 24.5 & 36 & 21.1 \\
\hline Other & 5 & 3.2 & 4 & 2.3 \\
\hline Sources Learn About E-Commerce Websites & 8 & 5.2 & 0 & 0.0 \\
\hline Recommendation from a friend & & & & \\
\hline Link from e-mail a e-commerce website sends & 71 & 23.7 & 56 & 20.2 \\
\hline Link from another website & 20 & 6.7 & 16 & 5.8 \\
\hline TV and radio & 29 & 9.7 & 31 & 11.2 \\
\hline Newspaper & 15 & 5.0 & 18 & 6.5 \\
\hline Magazine & 5 & 1.7 & 7 & 2.5 \\
\hline Social networking sites & 14 & 4.7 & 5 & 1.8 \\
\hline Search engine results & 78 & 26.1 & 50 & 18.1 \\
\hline Internet ads & 41 & 13.7 & 56 & 20.2 \\
\hline
\end{tabular}

The Pakistani and Turkish respondents found lack of confidence in after sale service $15.9 \%$ and $16.3 \%$ respectively, as the top factor that can likely dissuade them from purchasing online. A question was proposed to inquire the habits of the respondents as to what they do while they are using the internet. We can observe that $21.6 \%$ of the Pakistani respondents and $20.5 \%$ of Turkish participants spent their time on social networking sites. To analyze and have a brief idea of the consumer behavior of the participants, a question was introduced to probe what are the goods that the sample generally shops online. Table 5 shows that $18.2 \%$ of the Pakistani sample purchase electronic equipment online while $21.3 \%$ of Turkish respondents purchased books and periodicals. Other question asking about the payment methods, the results show that preference of both Pakistani and Turkish sample for credit or debit cards for their online shopping. Table 5 also indicates how respondents got to know about e-commerce website. The highest category for Pakistan is social networking sites with 78 respondents. The significant category for Turkish sample is search engine results and recommendation from a friend with 56 participants.

To have an insight into the construct product provided by online websites, a block of questions was arranged. As we can observe from Table 6 that the highest value is achieved by "product received fall short of expectation" (4.34) for Pakistan and (4.62) for Turkey meaning that it is closer to " 5 " and this means that the respondents "strongly agree" that their satisfaction levels were met by payment method options provided by the website. 
Customer Satisfaction in B2C E-commerce: A Comparative Study of Turkey and Pakistan

Table 6. Importance of Product Characteristic on Satisfaction Levels

\begin{tabular}{|c|l|c|c|c|c|}
\hline \multicolumn{2}{|c|}{} & \multicolumn{2}{c|}{ Pakistan } & \multicolumn{2}{c|}{ Turkey } \\
\cline { 3 - 6 } & W. Average & St.dev. & W. Average & St.dev \\
\hline 2 & Availability of products & 4.28 & 0.840 & 4.30 & 0.853 \\
\hline 3 & Range of products & 4.22 & 0.951 & 4.24 & 0.910 \\
\hline 4 & Puality of packaging & 3.82 & 0.957 & 3.90 & 1.134 \\
\hline
\end{tabular}

We asked 8 questions for understand importance of service provided by websites on satisfaction levels. We can observe from Table 7 that the highest value is achieved by "accuracy and completeness of shipment" options (4.74) for Pakistan and (4.60) for Turkey.

Table 7. Importance of Service Provided by Websites on Satisfaction Levels

\begin{tabular}{|c|l|c|c|c|c|}
\hline \multicolumn{2}{|l|}{} & \multicolumn{2}{c|}{ Pakistan } & \multicolumn{2}{c|}{ Turkey } \\
\cline { 3 - 6 } & W. Average & St.dev. & W. Average & St.dev. \\
\hline 1 & Service information quality & 3.84 & 0.726 & 3.92 & 1.106 \\
\hline 2 & Call center or online customer help service & 3.30 & 0.739 & 3.68 & 1.113 \\
\hline 3 & Service management & 3.54 & 0.673 & 3.64 & 1.038 \\
\hline 4 & Response and feedback & 3.56 & 0.810 & 3.92 & 1.232 \\
\hline 5 & Service attitude & 3.70 & 0.762 & 3.88 & 1.186 \\
\hline 6 & Timeliness of delivery & 4.62 & 0.993 & 4.54 & 0.864 \\
\hline 7 & Accuracy and completeness of shipment & 4.74 & 0.876 & 4.60 & 0.837 \\
\hline 8 & The delivering company & 2.70 & 1.174 & 3.20 & 1.328 \\
\hline
\end{tabular}

This means that the respondents "strongly agree" that their satisfaction levels were met by accuracy and completeness of shipment options provided by the website. According to these finding the shipping and delivering is an essential part of the B2C e-commerce. The network system is another essential part of the e-commerce website it was also investigated in our study. As we can see from Table 8 that "perceived privacy and security" carried the most weight with a score of 4.50 and 4.52 for both the samples meaning that this factor is the most important for online consumers, meaning that the samples from Pakistan and Turkey have are similar results.

Table 8. Importance of Network System on Satisfaction Levels

\begin{tabular}{|c|l|c|c|c|c|}
\hline \multicolumn{2}{|l|}{} & \multicolumn{2}{|c|}{ Pakistan } & \multicolumn{2}{c|}{ Turkey } \\
\cline { 3 - 6 } \multicolumn{2}{|l|}{} & W. Average & St.dev. & W. Average & St.dev. \\
\hline 1 & System accessibility & 4.26 & 0.812 & 4.32 & 0.859 \\
\hline 2 & Perceived privacy and security & 4.50 & 0.922 & 4.52 & 0.841 \\
\hline 3 & Effective guidance to entry errors & 3.84 & 0.879 & 3.94 & 0.904 \\
\hline 4 & $\begin{array}{l}\text { Technical problems during the ordering } \\
\text { or payment }\end{array}$ & 4.18 & 0.892 & 4.24 & 0.767 \\
\hline
\end{tabular}

To understand the importance of payment system for B2C e-commerce customer satisfaction a group of questions asked to respondents. According to the findings displayed in the Table 9, the "protection of payment information" carries most 
importance for Pakistani and Turkish participants with a weighted average of 4.18 and 4.74 respectively.

Table 9. Importance of Payment System on Satisfaction Levels

\begin{tabular}{|c|l|c|c|c|c|}
\hline \multicolumn{2}{|c|}{} & \multicolumn{2}{c|}{ Pakistan } & \multicolumn{2}{c|}{ Turkey } \\
\cline { 3 - 6 } & W. Average & St.dev. & W. Average & St.dev. \\
\hline 1 & Time lapse of order and delivery & 3.68 & 0.896 & 4.08 & 1.130 \\
\hline 2 & Payment method options & 3.90 & 0.894 & 4.02 & 1.045 \\
\hline 3 & Protection of payment information & 4.18 & 0.876 & 4.74 & 0.820 \\
\hline 4 & Delivery charges & 3.98 & 0.911 & 4.32 & 1.061 \\
\hline
\end{tabular}

As we can see from Table 10 that all privacy and security related issues are very important for customers. But "perceived privacy and security" carried the most weight with a score of 4.50 for Pakistani respondents and "reliable or trustworthy system" carried the most weight with a score of 4.50 for Turkish respondents.

Table 10. Importance of Privacy Protection on Satisfaction Levels

\begin{tabular}{|c|l|c|c|c|c|}
\hline \multicolumn{2}{|l|}{} & \multicolumn{2}{c|}{ Pakistan } & \multicolumn{2}{c|}{ Turkey } \\
\cline { 3 - 6 } & W. Average & St.dev. & W. Average & St.dev. \\
\hline 1 & Reliable or trustworthy system & 4.48 & 0.946 & 4.66 & 0.852 \\
\hline 2 & Perceived privacy and security & 4.50 & 0.922 & 4.52 & 0.841 \\
\hline 3 & Protection of private information & 4.40 & 0.956 & 4.58 & 0.823 \\
\hline 4 & $\begin{array}{l}\text { Lack of information on the seller, the } \\
\text { guarantee and consumer rights }\end{array}$ & 4.28 & 0.810 & 4.42 & 0.862 \\
\hline
\end{tabular}

To understand and find information regarding the website characteristic for B2C e-commerce customer satisfaction a bundle of questions was grouped to identify which factors of the website are important for the online consumers. According to the findings displayed in the Table 11, the "updated with recent most details" carries most importance for Pakistani and Turkish participants with a weighted average of 4.46 and 4.32 respectively.

\section{Table 11. Importance of Website Characteristic on Satisfaction Levels}

\begin{tabular}{|c|l|c|c|c|c|}
\hline \multicolumn{2}{|c|}{} & \multicolumn{2}{c|}{ Pakistan } & \multicolumn{2}{c|}{ Turkey } \\
\cline { 3 - 6 } & W.Average & St.dev. & W. Average & St.dev. \\
\hline 1 & Easy to use and understand & 4.34 & 1.050 & 4.12 & 0.885 \\
\hline 2 & Website layout and design & 4.04 & 0.947 & 3.94 & 1.034 \\
\hline 3 & Convenient navigation & 4.18 & 0.830 & 4.10 & 0.951 \\
\hline 4 & Convenient to search a product & 4.38 & 0.770 & 4.30 & 0.983 \\
\hline 5 & Updated with recent most details & 4.46 & 0.898 & 4.32 & 0.913 \\
\hline 6 & Easy to manage shopping basket & 4.12 & 0.896 & 4.04 & 0.962 \\
\hline 7 & Sufficient usage directions & 3.82 & 0.956 & 4.14 & 0.928 \\
\hline 8 & Process of completing product order & 4.42 & 0.918 & 4.40 & 0.921 \\
\hline
\end{tabular}

This section entailing a group of three questions was probing into the repurchase behavior of the participants involved in the research. As we can see from Table 12 that all of the participants "agree" that they will repurchase from the same 
website, tell others about this website and even recommend this online shopping website if they are satisfied from it. All the weighted average scores are above 4.

Table 12. Repurchase Behavior

\begin{tabular}{|c|l|c|c|c|c|}
\hline \multicolumn{2}{|c|}{} & \multicolumn{2}{c|}{ Pakistan } & \multicolumn{2}{c|}{ Turkey } \\
\cline { 3 - 6 } & W. Average & St.dev. & W. Average & St.dev. \\
\hline 1 & $\begin{array}{l}\text { I will keep repurchasing from the website I } \\
\text { use if I am satisfied }\end{array}$ & 4.24 & 0.560 & 4.50 & 0.850 \\
\hline 2 & $\begin{array}{l}\text { I am delighted to tell others that I shop } \\
\text { from a particular website if I am satisfied }\end{array}$ & 4.14 & 0.567 & 4.46 & 0.926 \\
\hline 3 & $\begin{array}{l}\text { I will definitely recommend this website to } \\
\text { my friends and co-workers if I am satisfied }\end{array}$ & 4.26 & 0.616 & 4.48 & 0.882 \\
\hline
\end{tabular}

\subsection{Comparison of Results from Pakistan and Turkey}

To compare and contrast the data sets obtained from the two samples, independent two sample t-tests have been employed to check if the means of the two samples are equal or different from each other. The hypothetical model for this research contains a total of 7 constructs that according to literature have an effect on the levels of online customer satisfaction. Minitab 17 statistical software was used to test and analyze the data sets from the two samples. To test the difference in the means of the variable product the data set from the questionnaire was inserted in the Minitab software coding Pakistan as " 1 " and Turkey as " 2 " to differentiate the two sample data. The confidence interval used for the entire construct was $95 \%$. The Figure 5 illustrates the result obtained from software. There is no difference in the means between Pakistan and Turkey for "Product" as the $p$-value is 0.789 which is greater than 0.05 meaning that there is no difference between the means.

The same methodology as the variable "Product" was applied to the variable "Service". As it is visible from Figure 5 plot that the means of the two countries have significant difference between them, it is affirmed by the p-value " 0.036 ", which is lower than 0.05 . This means that the variable "service" has different means and has different levels of online customer satisfaction in Pakistan and Turkey.

For "Network System" variable was asked in the survey with a total of 4 questions. In the Figure 5 , the p-value for this variable is greater than 0.05 , we can say that there is no difference in the means of the two samples and therefore this construct has the same levels of satisfaction for both the countries. This is also graphically depicted by the box-plot shown below. To investigate in the responses of both the countries towards characteristics related to the payment, a total of four questions were asked particularly to test this construct. As both the box plot and the greater p-value than 0.05 (0.451) indicates in Figure 5 that the means of two samples under consideration are not different at $95 \%$ significance level, it implies that the variable payment in online customer satisfaction is same in both the countries. 
Sahal M. SHEIKH \& Mehmet BASTI

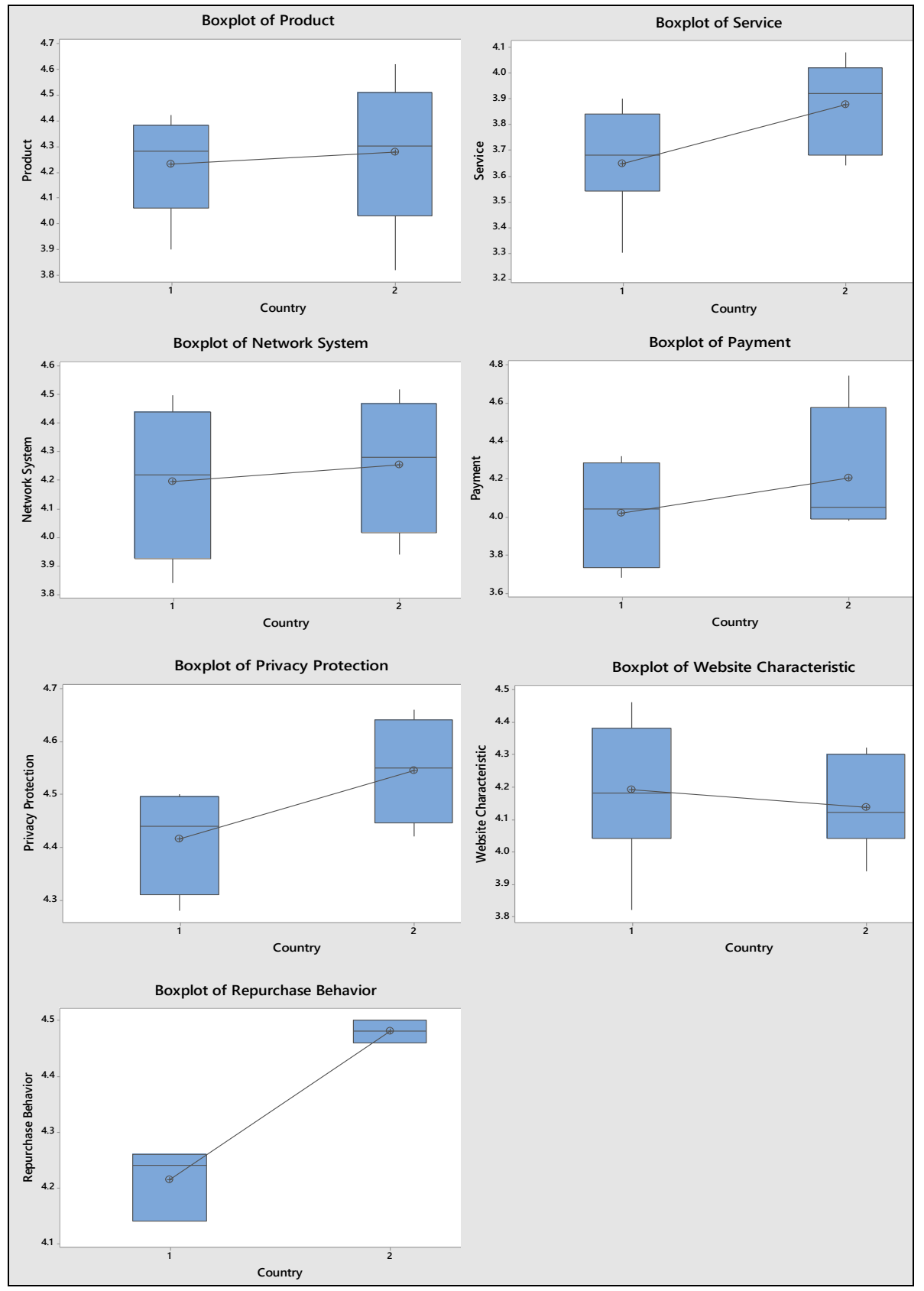

Figure 5: Comparison of Construct Variables 
The variable "Privacy Protection" was also tested in this study by the use of four questions placed at different places of the survey to have unbiased and non leading answers from the respondents of both countries. As we can see from Figure 5 that the $p$-value is greater than 0.05 and therefore we can comment that the means of the two samples from Pakistan and Turkey are same and they have same levels of customer satisfaction. The characteristic of a website plays an important role for a consumer to buy or shop online and therefore this variable was also explored to check the levels of satisfaction difference between Pakistan and Turkey. Looking at Figure 5, we can conclude upon viewing the diagram and the $p$-value of " 0.226 " that the means of the two samples are not different and therefore the levels of online customer satisfaction in Pakistan and Turkey are not different.

Repurchase behavior is a construct that is a dependent upon customer satisfaction. If a customer is satisfied then only according to the literature will the customer engage in re-purchasing behavior. As we can see from the box plot in Figure 5, the means are different from each other with quite a big average and also the $p$-value is lower than 0.05 . This means that there is a significant difference between the means of the sample groups and therefore the repurchase behavior is different in the two countries.

\subsubsection{Test of the Hypothesis of the Study}

To test the hypothesis of the study overall that there is no difference between the levels of online customer satisfaction between the two countries, all the weighted average questions are taken into consideration including the variables tested in isolation above. Two sample t-test is carried out for the questions 9 till 45 of the questionnaire. As it can be observed from the box plot in Figure 6, that the means from both the samples are not very much similar and that the $p$-value is greater than 0.05 .

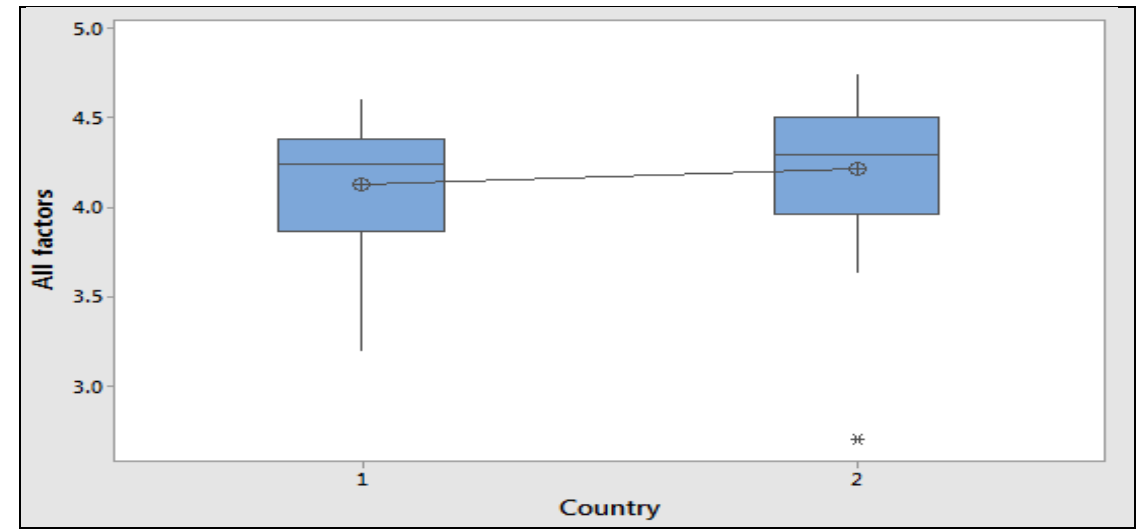

Figure 6. Comparison of Online Customer Satisfaction between Pakistan and Turkey 
This means that there is no difference between the levels of customer satisfaction between Pakistan and Turkey at 95\% significance level and we accept our null hypothesis and reject the alternate hypothesis.

Difference $=\mu(1)-\mu(2)$

Estimate for difference: -0.0881

95\% $\mathrm{Cl}$ for difference: $(-0.2608,0.0845)$

T-Test of difference $=0($ vs $\neq):$ T-Value $=-1.02 \mathrm{P}$-Value $=0.312 \mathrm{DF}=7$

\section{Conclusion}

It can be seen from the descriptive statistics that we do have small differences between the samples of the two countries but overall taking into consideration all the factors collectively, Pakistan and Turkey have similar B2C e-commerce customer satisfaction. We saw in this study that the construct service and repurchase behavior were the only two constructs having difference in the means of the samples. This means that Pakistani and Turkish respondents have different attitudes and preference concerning these two cognitive factors. It was also noted that the Pakistani online customers prefer time and energy to be saved and therefore engage in online shopping. Whereas, Turkish online customers believe that it is financially more effective to purchase online goods and services as they can find products with less price.

The influence of social networking sites for both the sample is strong as both the samples engage in social networking sites while surfing the internet and also find information regarding e-commerce sites from there. The friends also have an important role in influencing and passing word-of-mouth information about an ecommerce website. However, Turkish respondents also tend to find e-commerce website more from search engine results compared to the sample of Pakistan.

The respondents from Pakistan and Turkey both prefer credit or debit card payment first and then off-line payment methods compared to other type of payments. This also demonstrates the similarity in nature and attitude of both the samples under consideration. Pakistani online customers buy shop for electronic equipments for the most and touristic service for the second. The second category for Turkey is also the same and as Istanbul is the touristic capital of Turkey it was expected. However, the first category of goods bought by Turkish respondents is books and periodicals. For both Pakistan and Turkey the factor that can dissuade them from buying online is the lack of confidence in the after sale service. This means that both the sample give high value to the after sale service and this area is to be considered by e-commerce website in both the countries.

The use of descriptive statistics and two sample t-test has provided this study a descriptive statistical analysis as well as numerical statistics to probe and scrutinize 
the differences and similarities between the two countries. The descriptive statistics highlighted some of the differences in attitudes and preferences between the participants of the two countries. The social media use and touristic information from the internet were one of the common areas for the two countries. As compared with the Neilsen report of 2014, this is also one of the most highly used and bought services and therefore this study walks in parallel lines with the literature. Both the literacy rate and internet penetration is high in Turkey and therefore we can observe that Turkey has books and periodicals bought the most and high number of respondents shopping online from 5 years or more.

The recommendation of e-commerce B2C websites for both countries is to investigate and learn the culture and traditions and then shape the website. The website characteristic and attributes contain a huge significance for the online consumer as per this research therefore the design of the website should be appealing and user friendly. The security of information and payment is also one of the most highly weighted and valued variables from both the countries. The ease of navigation and delivery time that the product takes also has a considerable impact on the customer satisfaction levels therefore the time and date should be mentioned and prices according to the delivery time can be allotted. For example if the delivery is urgently required by the respondent it could be charged higher than a normal delivery process. This technique is effective for both the consumers and supplier economically.

E-commerce website should invest in more advertisement on the social media as this is the activity both the countries participant engaged more. Also it was seen that very few people managed to gain knowledge of e-commerce from radio, TV and magazine. Therefore, this could be the platforms that e-commerce B2C companies should try and explore. The lack of confidence in after sale service is the factor that most likely dissuades the participants from buying online. Therefore the $\mathrm{B} 2 \mathrm{C}$ organization have to provide more information and innovative techniques in this realm to make this fear fade away and attract more and more customer. This factor can be dealt with providing warranty information, money back guaranty and free maintenance and repair services.

The study now focuses on just the two countries. A research in future can be done including other countries to have a better picture for the $\mathrm{B} 2 \mathrm{C}$ e-commerce satisfaction. Furthermore, this research has only focused upon one type of ecommerce satisfaction which is of business-to-consumer. The next researches can be done on other types that are mentioned in study. Technology is growing and expanding second by second and therefore more advancements and innovation are required in this realm to make the purchase behavior easier and convenient for the customers. This platform needs more attention from entrepreneurs and requires added facilities that can be attached to evolve this revolutionary online channel created since its inception. 


\section{References}

Bai, B., Law, R., \& Wen, I. (2008). The impact of website quality on customer satisfaction and purchase intentions: Evidence from Chinese online visitors. International Journal of Hospitality Management, 27(3), 391-402. http://dx.doi.org/10.1016/j.ijhm.2007.10.008

Barutcu, S. (2008). Perakendecilik Sektöründe Teknolojik Değişim: E-Perakendecilik, E-Mağaza Bağ|ıı̆ı̆ ve E-Mağaza Bağ|ılı̆ıını Etkileyen Faktörler. Süleyman Demirel Üniversitesi İktisadi ve İdari Bilimler Fakültesi Dergisi, 13(1).

Blythe, S. E. (2006). Pakistan Goes Digital: The Electronic Transactions Ordinance as a Facilitator Growth for E-Commerce. J. Islamic St. Prac. Int'I L., 2, 5.

Brilliant, M. A., \& Achyar, A. (2013). The impact of satisfaction and trust on loyalty of e-commerce customers. ASEAN Marketing Journal, 5(1), 51-58.

Campo, S., \& Yagüe, J. M. (2009). Exploring non-linear effects of determinants on tourists' satisfaction. International Journal of Culture, Tourism and Hospitality Research, 3(2), 127138. http://dx.doi.org/10.1108/17506180910962131

Cardozo, R. N. (1965). An experimental study of customer effort, expectation, and satisfaction. Journal of marketing research, 244-249. http://dx.doi.org/10.2307/3150182

Celik, H. E., \& Yilmaz, V. (2011). Extending the technology acceptance model for adoption of e-shopping by consumers in Turkey. Journal of Electronic Commerce Research, 12(2), 152164.

Chen, Z., \& Dubinsky, A. J. (2003). A conceptual model of perceived customer value in e-commerce: A preliminary investigation. Psychology and Marketing, 20(4), 323-347. http://dx.doi.org/10.1002/mar.10076

Chaffey, D. (2009). E-business and E-commerce Management: Strategy. Implementation and practice, Prentice Hall Publications.

Eid, M. I. (2011). Determinants of e-commerce customer satisfaction, trust, and loyalty in Saudi Arabia. Journal of Electronic Commerce Research, 12(1), 78-93.

Ernst and Young (2001). Global Online Retailing, 23-31.

Gefen, D., \& Straub, D. W. (2003). Managing user trust in B2C e-services. E-service Journal, 2(2), 7-24. http://dx.doi.org/10.2979/ESJ.2003.2.2.7

Giese, J.L. \& Cote, J.A. (2000). Defining consumer satisfaction, Academy of Marketing Science Review, 1, 1-34.

Gupta, S., \& Zeithaml, V. (2006). Customer metrics and their impact on financial performance. Marketing Science, 25(6), 718-739. http://dx.doi.org/10.1287/mksc.1060.0221

Gupta, M., Narasimhan, C., Niraj, R., \& Foster, G. (2003). Understanding Customer Level Profitability Implications of Satisfaction Programs. Working Paper Series, Teradata Center for Customer Relationship Management, Duke University.

Hair, J.F. \& Keep, W.W. (1997) 'Electronic Marketing: Future Possibilities', in Patterson, R.A. (ed.), Electronic Marketing and the Consumer, Thousand Oaks: Sage, 163-174.

Jennex, M. E., Amoroso, D., \& Adelakun, O. (2004). E-commerce infrastructure success factors for small companies in developing economies. Electronic Commerce Research, 4(3), 263-286. http://dx.doi.org/10.1023/B:ELEC.0000027983.36409.d4

Jianchi, X., \& Xiaohong, C. (2009). Customer Satisfaction of E-Commerce Websites. In 2009 International Workshop on Intelligent Systems and Applications (pp. 1-5). 
Jie, Y. U., Subramanian, N., Ning, K., \& Edwards, D. (2015). Product delivery service provider selection and customer satisfaction in the era of internet of things: A Chinese e-retailers' perspective. International Journal of Production Economics, 159, 104-116.

Kaleem, A., \& Ahmad, S. (2008). Bankers' perceptions of electronic banking in Pakistan. Journal of Internet Banking and Commerce, 13(1), 1-16.

Kaynak, E., Tatoglu, E., \& Kula, V. (2005). An analysis of the factors affecting the adoption of electronic commerce by SMEs: Evidence from an emerging market. International Marketing Review, 22(6), 623-640. http://dx.doi.org/10.1108/02651330510630258

Korkmaz, N. (2002). Sorularla Internet ve E- ticaret Rehberi (Internet and E-commerce Guide with Questions), Istanbul: ITO Publications, 52-53.

Lightner, N. J., Yenisey, M. M., Ozok, A., \& Salvendy, G. (2002). Shopping behavior and preferences in e-commerce of Turkish and American university students: implications from cross-cultural design. Behaviour and Information Technology, 21(6), 373-385.

Lin, H. F. (2007). The impact of website quality dimensions on customer satisfaction in the B2C e-commerce context. Total Quality Management and Business Excellence, 18(4), 363378. http://dx.doi.org/10.1080/14783360701231302

Malhotra, P., \& Singh, B. (2009). The impact of internet banking on bank performance and risk: The Indian experience. Eurasian Journal of Business and Economics, 2(4), 43-62.

Meyer, A., \& Taylor, P. (2000). E-commerce-an introduction. Computing and Control Engineering Journal, 11(3), 107-108. http://dx.doi.org/10.1049/cce:20000301

Moliner, B. (2004). La formacio'n de la satisfaccio'n/insatisfaccio'n del consumidor y del comportamiento de queja: aplicación al a'mbito de los restaurantes, tesis doctoral, Departamento de Direccio'n de Empresas, Universidad de Valencia, Valencia

Moxon, R. W. (2001). Introduction to the symposium e-commerce and global business: The impact of the information and communication technology revolution on the conduct of international business. Journal of International Business Studies, 32(4), 617-639. http://dx.doi.org/10.1057/palgrave.jibs.8490988

Nielsen, N. V. (2014). E-commerce: Evolution or revolution in the fast-moving consumer goods world.

OECD (1999a).Policy and Regulation Issues for the Network-Based Content Services, Paris: Organization for Economic Cooperation and Development (Working Party on the Information Economy), Doc. DSTI/ICCP/IE(96)9/FINAL.

OECD (2000a).Electronic Commerce- Existing GATS Commitments for Online Supply of Services, Paris: Organization for Economic Cooperation and Development (Trade Directorate), Doc. TD/TC/WP(99)37/Final

OECD (2000b).Electronic Commerce: Initial Survey Of Unilateral Liberalization And Facilitation Measures, Paris: Organization for Economic Cooperation and Development (Trade Directorate), Doc. TD/TC/WP(99)38/Final.

OECD (2000c).Quantification Of The Costs To National Welfare Of Barriers To Trade In Services, OECD Working Party of the Trade Committee Scooping Paper, 4-5 December, 2000, Paris: Organization for Economic Cooperation and Development.

Oliver, R.L. (1997). Satisfaction: A Behavioral Perspective on the Consumer. New York: McGraw-Hill. 
Parker, C. \& Mathews, B.P. (2001). Customer satisfaction: contrasting academic and consumers' interpretations. Marketing Intelligence and Planning, 19(1), 38-44. http://dx.doi.org/10.1108/02634500110363790

Seyal, A. H., Awais, M. M., Shamail, S., \& Abbas, A. (2004). Determinants of electronic commerce in Pakistan: Preliminary evidence from small and medium enterprises. Electronic Markets, 14(4), 372-387. http://dx.doi.org/10.1080/10196780412331311801

Shankar, V., Smith, A. K., \& Rangaswamy, A. (2003). Customer satisfaction and loyalty in online and offline environments. International Journal of Research in Marketing, 20(2), 153175. http://dx.doi.org/10.1016/S0167-8116(03)00016-8

Singh, M. (2002). E-services and their role in B2C e-commerce. Managing Service Quality: An International Journal, 12(6), 434-446. http://dx.doi.org/10.1108/09604520210451911

Statista (2015, June 20). B2C E-Commerce Sales Worldwide From 2012 to 2018. Retrieved on June 20, 2015, from Statista website: http://www.statista.com/statistics/261245/b2c-ecommerce-sales-worldwide/

Subramanian, N., Gunasekaran, A., Yu, J., Cheng, J., \& Ning, K., (2014). Customer satisfaction and competitiveness in the Chinese e-retailing: structural equation modeling (SEM) approach to identify the role of quality factors. Expert System with Application 41 (1), 69-80. http://dx.doi.org/10.1016/j.eswa.2013.07.012

Sulaiman, A., Mohezar, S., \& Rasheed, A. (2007). A trust model for e-commerce in Pakistan: An empirical research. Asian Journal of Information Technology, 6(2), 192-199.

Swan, J.E. and Combs, L.J. (1976).Product performance and consumer satisfaction: a new concept, Journal of Marketing, 40, (7), 25-33.

Westbrook, R.A., \& Oliver, R.L. (1991).The dimensionality of consumption emotion patterns and consumer satisfaction. Journal of Consumer Research, 18(14), 84-91. http://dx.doi.org/10.1086/209243

Yahia, I. B. (2005). Non commercial B2C virtual communities: definition and classification an exploratory qualitative study. IADIS International Journal on WWW/Internet, 5(1), 129-144.

Zhang, X., Prybutok, V., \& Huang, A. (2006). An empirical study of factors affecting e-service satisfaction. Human systems management, 25(4), 279. 